Paolo Gava, engineer, master athlete and amateur scientist

Eur J Transl Myol 31 (4): 10260, 2021 doi: 10.4081/ejtm.2021.10260

\title{
Paolo Gava, a professional engineer, who has become a Master athlete, an amateur scientist and a lifelong friend
}

\author{
Ugo Carraro (1,2,3), Helmut Kern (4,5,6), Giovanna Albertin (1,7)
}

(1) CIR-Myo - Interdepartmental Research Center of Myology, University of Padova, Italy; (2) Department of Biomedical Sciences (DBS), University of Padova, Italy; (3) A\&C M-C Foundation for Translational Myology, Padova, Italy; (4) Physiko- und Rheumatherapie, St. Pölten, Austria; (5) Ludwig Boltzmann Institute of Rehabilitation Research, St Pölten, Austria; (6) Institute of Physical Medicine and Rehabilitation, Prim. Dr. H Kern GmbH, Amstetten, Austria; (7) Department of Neuroscience (DNS), Section of Human Anatomy, University of Padova, Italy.

This article is distributed under the terms of the Creative Commons Attribution Noncommercial License (CC BY-NC 4.0) which permits any noncommercial use, distribution, and reproduction in any medium, provided the original author(s) and source are credited.

\begin{abstract}
Paolo Gava, (Conegliano, Treviso, September 1, 1946 - Stra, Venezia, Italy, July 19, 2021) was a sustainable resources engineer, who worked in Italy, France and England, leading research programs well before the current international interest in countering global warming. Passionate about Tango, Paolo kept himself in shape for many decades by running or pedaling or rollerskating, after years of training as a semi-professional athlete, competing and winning Italian and European short distance races in the Master classes. Then, Paolo applied his engineering skills to optimize comparisons between the results of the different Classes of Master Athletes, questioning the rules used by Italian and World Master Sports Associations. Friendly discussing during an after-dinner, he shocked us claiming that, in absence of diseases and trauma (Early Aging), the aging decay is a linear process from 30 to 110 years. Under our friendly pressure he was able to publish his first biomedical article, detailing his mathematical approaches and results in a 2015 issue of Experimental Aging Research, titled: Age-associated power decline from running, jumping and throwing male master world records. To honor his other legacies during his last six years of life, we add here further examples of Paolo's scientific studies and his relationships with senior colleagues and young students of sports and aging sciences.
\end{abstract}

Key Words: Paolo Gava; Master athlete; Master World Records; aging and sports sciences.

Paolo Gava (Conegliano, Treviso, Italy September 1, 1946 - Stra, Venezia, Italy, July 19, 2021) was an engineer specialized in sustainable energy resources. He worked in Venice (Italy), Montecarlo (France), The Hague (Netherlands) and London (England), leading research programs well before the current international interest in fight against global warming. Passionate about Tango (Figure 1), Paolo kept himself in shape for many decades by running or pedaling or roller-skating, after years of training as a semi-professional athlete, who competed and winned Italian and European short distance races in the Master classes. After retirement from the races, Paolo applied his engineering skills to optimize comparisons between the results of the different Categories of Master Athletes, questioning the rules used by Italian and World Master Sports Associations.

Friendly discussing during an after-dinner, he shocked us claiming that, in absence of diseases and trauma (i.e., of

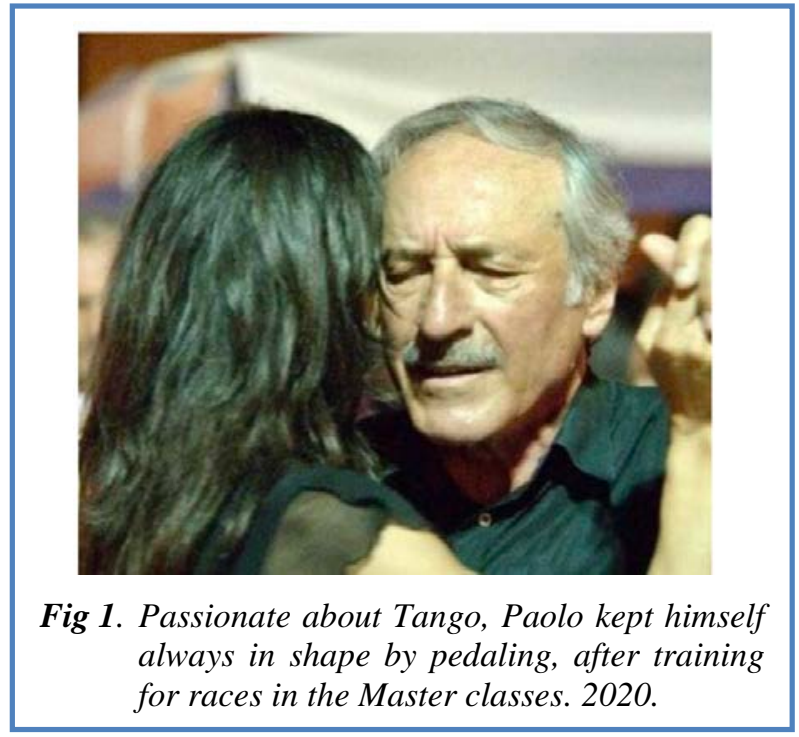




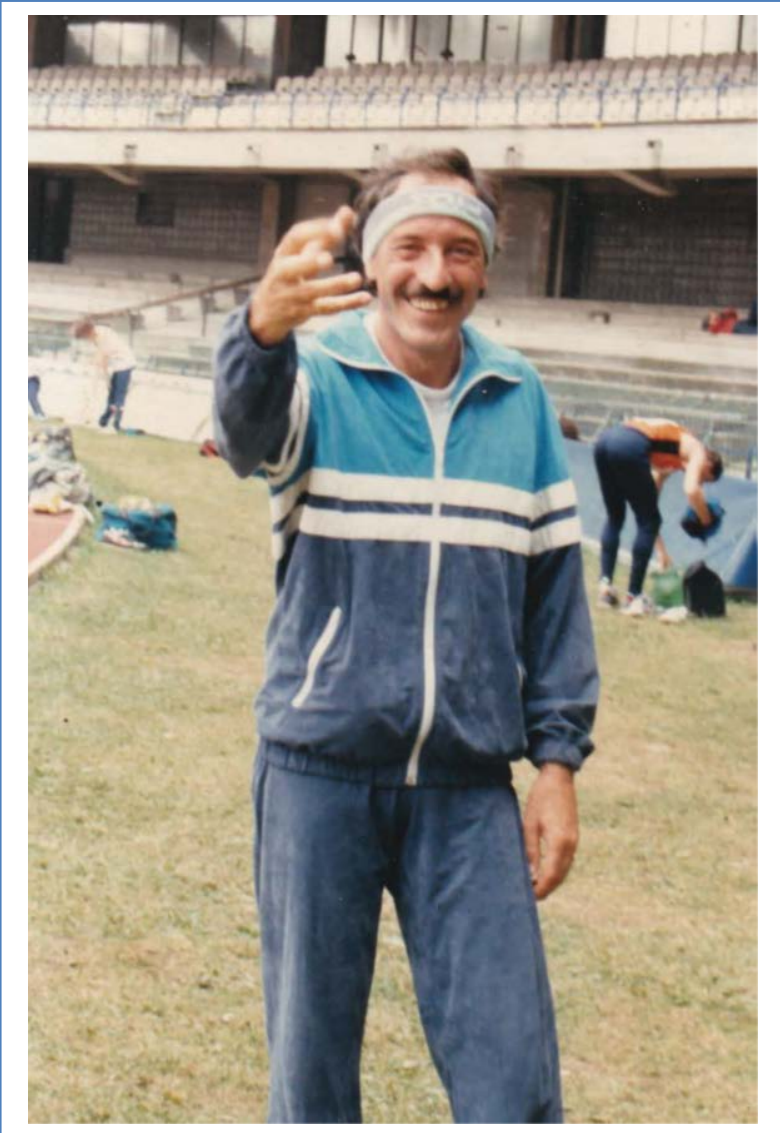

Fig 2. Paolo Gava as a Master Athlete in 1989.

Early Aging), the aging decay is an almost linear process from 30 to 110 years. Under our friendly pressure he was able to publish his first biomedical article, detailing his mathematical approaches and results, in a 2015 issue of Experimental Aging Research, titled: "Age-associated power decline from running, jumping and throwing male master world records". ${ }^{1}$ To honor his other legacies during his last six years of life, we add further examples of Paolo's scientific studies and of his relationships with senior colleagues and young students of Aging and Sports curricula. ${ }^{2-7}$

\section{Paolo Gava as a Master Athlete}

Figure 2. depicts Paolo when, in his forties, competed in short-run Master classes. He participated to several Italian and European races, winning the 100 meters Italian race in 1988. He also competed in the 400 meters race up to 1991.

\section{Paolo Gava as an amateur scientist}

As stated in the Abstract of his 2015 seminal first paper: ${ }^{1}$ Absolute male world records of 16 events were collected along with world records of male Masters categories. Performance was normalized with respect to the absolute record; the performance of various age groups is consequently represented by a number ranging from 1 (world absolute records) to 0 (null performance). Throwing events are further normalized for the

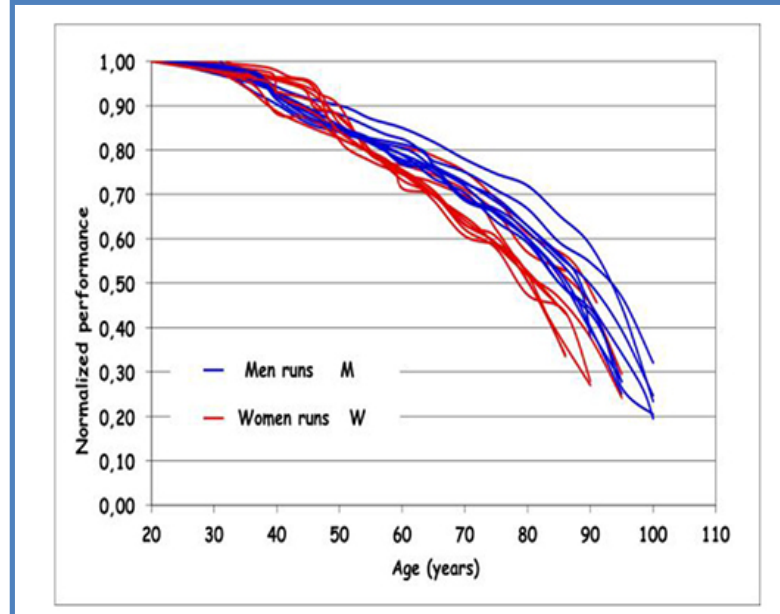

Fig 3. Comparison of normalized running parameters of male (blue) and female (red) Masters Athletes. Decline trends of World Records of the running disciplines are very similar. They are very gentle from 30 to 50 years, almost linear from 50 to 70 years and then the decays are progressively steeper. Reprinted with permission from Gava $P$, Giuriati W, Ravara B. Gender difference of aging performance decay rate in normalized Masters World Records of Athletics: much less than expected. Eur J Transl Myol. 2020 Apr 1;30(1):8869. doi: 10.4081/ejtm.2019.8869. ${ }^{7}$

decreasing weight of the implements with the increasing age of the Masters athletes. Male world records of track and field events were taken from the websites of the International Association of Athletics Federation (IAAF) for absolute world records (http://www.iaaf.org/) and the World Masters Athletics (WMA) for Masters world records (http://www.world-masters-athletics.org/). The main unxpected result was summarized in Gava et al. 2015:1 "Human power decline in Masters athletes was analyzed, adopting a coherent approach based on an extended database. Skeletal muscle power starts declining after the age of 30. The various trend lines point to 0 at the age of 110 years, which is in line with the present human survival age".

Figure 3 shows his latest results, published in 2020, i. e., the comparison of the normalized decay rate for agedependent performance in the men's and women's world records of Masters categories. Once again, the expected gender differences that characterize absolute values in sports activities did not occurred, something fully unexpected in gender-related sports behaviours. Implications have long-term influences on biology, physiopathology and managements of aging.

\section{Paolo Gava and the Venicemarathon}

The marathon is the most classic Olympic running event, but in several cities around the world it has become very 
popular with increasing participation over the past 20 years. The growing popularity of the marathon has led to a significant increase in participants, especially Master athletes. ${ }^{8-11}$ There is evidence that long-distance running could provide long term health benefits for older runners. ${ }^{12}$ As a former Master Athlete, Paolo had the opportunity to contact the president and organizers of the Venicemarathon and convince them to provide a long series of data with the aim of analyzing them with his dimensionless analysis method. In collaboration with him, some of us have analyzed data of different editions of this famous Italian race that attracts people from all over the world. The race starts outside Venice, usually near Stra (Venice) then runs along the Brenta Riviera into the city, crossing there the canals through floating bridges set up for the race. So far, a student from the Sports Curriculum discussed the Venice Marathon data in his graduation thesis. ${ }^{5}$ Furthermore, we analyzed the data to describe the gender distribution of participants in 17 editions from 2003 to 2019, but for age groups and nationality only in the 13 editions from 2007 to 2019. Data published as an EJTM Communication in this issue show that there has been a steady increase of female participation, from $12.35 \%$ in 2003 to $22.27 \%$ in $2019 .{ }^{13}$ Using Paolo's approaches we will further compare the performance of different athletes by category, highlighting the trends over the years and the physiological decline regardless of the absolute values of performances.

\section{Paolo Gava as an engineer who loved cycling training} and cycle tourism

Paolo as an amateur cyclist loved cycling the Brenta Riviera that connects Padua to Venice along running waters and embankments. Annoyed by the kilometers shared with the risky car traffic, he studied and developed detailed plans to avoid those busy roads, proposing to connect Venice to Padua along a reserved cycle path. He also presented his detailed plans to the municipal and regional authorities, but unfortunately to date without success. We are confident that sooner or later with support of amateur cycling associations and the growing value of cycle tourism, his pioneering project will be implemented following his pioneering path.

Unfortunately, in the last year Paolo has suffered from an incurable disease. He died in his beloved house in Stra (Venice) on the night of July 19th, 2021. Paolo was a sensitive and intellectuall person who loved and was loved by his family, colleagues and friends. We will never forget Paolo's generosity and exceptional positive approach to life.

\section{List of acronyms}

IAAF - International Association of Athletics Federation WMA - World Masters Athletics

\section{Authors' contributions}

UC, HK, GA: drafting and approval of the manuscript.

\section{Acknowledgments}

A\&C M-C Foundation for Translational Myology, Padova, Italy and PAGEpress, Scientific Publications, Pavia, Italy sponsored this Obituary.

\section{Funding None}

\section{Conflict of Interest}

The authors declare no competing interests.

\section{Ethical Publication Statement}

We confirm that we have read the Journal's position on issues involved in ethical publication and affirms that this report is consistent with those guidelines.

\section{Corresponding Author}

Ugo Carraro, Department of Biomedical Sciences, University of Padova, Via Ugo Bassi, 58/B 35131 Padova, Italy.

ORCID iD: 0000-0002-0159-3245

E-mail: ugo.carraro@unipd.it

\section{E-mail and ORCID iD of co-author}

HelmutKern: helmut@kern-reha.at

ORCID iD: 0000-0001-9661-8814

Giovanna Albertin: giovanna.albertin@unipd.it ORCID iD: 0000-0002-7551-4431

\section{References}

1. Gava P, Kern H, Carraro U. Age-associated power decline from running, jumping, and throwing male masters world records. Exp Aging Res. 2015;41(2):115-35. doi: 10.1080/0361073X.2015. 1001648.

2. Carraro U, Kern H, Gava P, Hofer C, Loefler S, Gargiulo P, Mosole S, Zampieri S, Gobbo V, Ravara B, Piccione F, Marcante A, Baba A, Schils S, Pond A, Gava F. Biology of Muscle Atrophy and of its Recovery by FES in Aging and Mobility Impairments: Roots and By-Products. Eur J Transl Myol. 2015 Aug 25;25(4):221-30. doi: 10.4081/ejtm.2015.5272.

3. Carraro U, Kern H, Gava P, Hofer C, Loefler S, Gargiulo P, Edmunds K, Árnadóttir ÍD, Zampieri S, Ravara B, Gava F, Nori A, Gobbo V, Masiero S, Marcante A, Baba A, Piccione F, Schils S, Pond A, Mosole S. Recovery from muscle weakness by exercise and FES: lessons from Masters, active or sedentary seniors and SCI patients. Aging Clin Exp Res. $2017 \quad$ Aug;29(4):579-590. doi: 10.1007/s40520-016-0619-1. Epub 2016 Sep 3.

4. Gava P, Giuriati W, Ravara B. Gender difference of aging performance decay rate in normalized Masters World Records of Athletics: much less than expected. Eur J Transl Myol. 2020 Apr 1;30(1):8869. doi: 10.4081/ejtm.2019.8869.

5. Zuccon D. Analisi della partecipazione e della prestazione di atleti senior machili e femminili in diverse edizioni della Venicemarathon. University 
of Padova. Thesis in Sport Sciences (Italian with English summary).

6. Timing Data Service: https://tds.sport/it

7. Stones MJ. Age Differences, Age Changes, and Generalizability in Marathon Running by Master Athletes. Front Psychol. 2019 Sep 20;10:2161. doi: 10.3389/fpsyg.2019.02161.

8. Running USA. Available online: https://www.runningusa.org// (accessed on 15 February 2019)

9. Anthony D. Differences in Participation and Performance Trends in Age Group Half and Full Marathoners. Chin. J. Physiol. 2015, 57, 209-219 doi: 10.4077/cjp.2014.bac219

10. Nikolaidis PT, Cuk I, Rosemann T, Knechtle B. Performance and Pacing of Age Groups in HalfMarathon and Marathon. Int J Environ Res Public Health. 2019 May 20;16(10):1777. doi: 10.3390/ijerph16101777.

11. Leyk D, Erley O, Gorges W, Ridder D, Rüther T, Wunderlich M, Sievert A, Essfeld D, Piekarski C, Erren T. Performance, training and lifestyle parameters of marathon runners aged 20-80 years: results of the PACE-study. Int J Sports Med. 2009 May;30(5):360-5. doi: 10.1055/s-0028-1105935. Epub 2009 Mar 10.

12. Marzetti E, Calvani R, Tosato M, Cesari M, Di Bari M, Cherubini A, Broccatelli M, Savera G, D'Elia M, Pahor M, Bernabei R, Landi F; SPRINTT Consortium. Physical activity and exercise as countermeasures to physical frailty and sarcopenia. Aging Clin Exp Res. 2017 Feb;29(1):35-42. doi: 10.1007/s40520-016-0705-4. Epub 2017 Feb 8.

13. Albertin G, Astolfi L, Falda M, Zuccon D, Ravara B, Kern H, Ferrante G, De Caro R, Guidolin D. "Venice marathon": participation of female Master Athletes shows a constant increase from 2003 to 2019. Eur J Transl Myol. 31 (4): 10266, 2021. doi: 10.4081/ejtm.2021.10266.

Submitted: October 28, 2021 Accepted for publication: November 01, 2021 